\title{
Reflexão metodológica sobre o trabalho de campo de pesquisa internacional multicêntrica Brasil-Canadá
}

\author{
Methodological reflection about the fieldwork of an international \\ multisite research Brazil-Canada \\ Reflexión metodológica sur el trabajo de campo de la investigación \\ internacional multi sitio Brasil-Canadá
}

\section{Margareth Santos Zanchetta ${ }^{1}$ (i) Walterlânia Silva Santos ${ }^{2}$ (B) Kleyde Ventura de Souza ${ }^{3}$ (D) Alecssandra de Fátima Silva Viduedo² (1) Hannah Argumedo-Stenner ${ }^{4}$ (1) Dakota Carrie ${ }^{1}$ (1) Francesca Aviv ${ }^{4}$ (1) Hilary Hwu ${ }^{1}$ (B) Hannah Stahl ${ }^{1}$ (]) Vanessa Fofie ${ }^{1}$ (1) Dorin d'Souza ${ }^{1}$ (1) Milena Oliva ${ }^{1}$ (D) John Tadeo ${ }^{1}$ (1) Edwaldo Costa ${ }^{1,5}$ (1) Francisco Vilela ${ }^{6}$ (D) Andréa Carvalho ${ }^{6}$ (1) \\ Haydée Padilla Vda de Escobar ${ }^{7}$ (1) Ingryd Cunha Ventura Felipe ${ }^{1}$ (b)}

1. Ryerson University, Faculty of Community Services, Daphne Cockwell School of Nursing. Toronto, Canadá.

2. Universidade de Brasília, Faculdade de Ceilândia. Brasília, DF, Brasil.

3. Universidade Federal de Minas Gerais. Belo Horizonte, MG, Brasil.

4. Ryerson University, Faculty of Community Services, School of Social Work. Toronto, Canadá.

5. Marinha do Brasil. Brasília, DF, Brasil.

6. Sindicato dos Agentes Comunitários de Saúde do Estado do Rio de Janeiro. Rio de Janeiro, RJ, Brasil.

7. Organização Pan-Americana de Saúde. Brasília, DF, Brasil.

Autor correspondente:

Margareth Santos Zanchetta.

E-mail: mzanchet@ryerson.ca.

Recebido em 16/09/2020.

Aprovado em 16/10/2020.

\section{Resumo}

Objetivo: Apresentar o resultado de uma reflexão metodologicamente estruturada sobre o caminho trilhado em todas as fases de uma pesquisa internacional no Brasil sobre a implementação do Programa de Humanização do Pré-natal e do Nascimento e seus atores sociais. Método: Método reflexivo de pesquisa que conduz à percepção modificada de uma dada situação levando a novas ideias, com o potencial de revelar temas de análise e engendrar propostas de possíveis soluções com desenho de um plano de ação. $O$ objeto das reflexões concentrou-se nas participações dos copesquisadores de um estudo etnográfico internacional, multidisciplinar e multicêntrico implantado em Junho/2019-Março/2020. Resultados: As reflexões indicam sensibilidade sobre o tema e silêncio imposto em relação à violência obstétrica. Sob múltiplas manifestações da violência institucionalizada, constatou-se ações como resistência ao assunto na rede hospitalar, negligência e questionamentos distorcidos nos espaços políticos de autorização para a anuência institucional. A demora por comitê de ética colocando em risco o calendário de conclusão da condução da pesquisa, exigido por agência estrangeira de fomento. Conclusão e implicação para a prática: A reflexão estruturada possibilitou um processo ímpar de aprendizagem para os copesquisadores navegando em distintas culturas universitárias e sociais de pesquisa.

Palavras-chave: Direitos da Mulher; Pesquisa Metodológica em Enfermagem; Pesquisa Qualitativa; Saúde Global; Violência contra a Mulher.

\section{Abstract}

Aim: To present the results of a structured reflection on the methodological phases of an international research in Brazil regarding the implementation of the Program of Humanization of Prenatal and Childbirth, as well as, reflection on the project's social actors. Method: A reflective research method that modifies the perception of a given situation, leading to new ideas, revealing themes of analysis, and engendering proposals for possible solutions with the creation of an action plan. The object of the reflection was the participation of co-investigators in an international, multidisciplinary, and multisite ethnographic study, implemented in June/2019-March/2020. Results: The reflections indicate emotional sensitivity to the theme and silence about obstetric violence. There are multiple manifestations of institutionalized violence including resistance to confronting obstetric violence in hospital settings, negligence and distorted questioning in the political spaces of organizational authorization. The delay caused by a research ethics committee which put the timetable for completion of research development at risk by requiring funding from a foreign agency. Conclusion and implication for practice: Structured reflection allowed a unique learning process for co-investigators navigating different university and social research cultures.

Keywords: Global Health; Nursing Methodology Research; Qualitative Research; Violence Against Women; Women's Rights.

\section{REsumen}

Objetivo: Presentar resultados de una reflexión estructurada metodológicamente sobre el camino metodológico seguido en todas las fases de una investigación internacional en Brasil sobre la implementación del Programa de Humanización del Cuidado Prenatal y el Nacimiento y sus actores sociales. Método: Método de investigación reflexiva que conduce a una percepción modificada de una situación dada, dando lugar a nuevas ideas, con el potencial de revelar temas de análisis y generar propuestas de posibles soluciones con el diseño de un plan de acción. El objeto de las reflexiones se centró en la participación de los co-investigadores en una investigación etnográfica internacional, multidisciplinar y multi sitio implementada en Junio / 2019-Marzo / 2020 Resultados: Las reflexiones indican sensibilidad sobre el tema y silencio impuesto en relación a la violencia obstétrica. Bajo múltiples manifestaciones de violencia institucionalizada, hubo acciones como resistencia al tema en el ámbito hospitalario, negligencia y cuestionamientos distorsionados en los espacios políticos de autorización para el consentimiento institucional y demora por parte del comité de ética, poniendo en riesgo el calendario para completar la realización de la investigación requerida para una agencia de desarrollo extranjera. Conclusión e implicación para la práctica: La reflexión estructurada permitió un proceso de aprendizaje único para los co-investigadores que navegaron en diferentes culturas universitarias y de investigación social.

Palabras clave: Derechos de la Mujer; Investigación Metodológica en Enfermería; Investigación Cualitativa; Salud Global; Violencia contra la Mujer. 


\section{INTRODUÇÃO}

A pesquisa no contexto de saúde global investiga temas considerados sensíveis, na perspectiva dos indivíduos, comunidades, instituições e governos. A operacionalização da pesquisa sobre a sensitividade social requer maior clarificação metodológica e conceitual devido à complexidade de se estudar grupos sociais estigmatizados, em desvantagem social ou socialmente negligenciados. ${ }^{1} \mathrm{O}$ trabalho de campo requer habilidades para harmonizar culturas distintas de pesquisa, manejar diferenças de entendimento sobre questões éticas na pesquisa e atenuar o poder institucional e a interferência de autoridade política que, conjuntamente, podem ameaçar a liberdade e a autonomia do pesquisador. ${ }^{2}$

A violação de direitos humanos - de particular interesse das organizações internacionais, cujas decisões têm impactos econômicos, políticos e sociais nos Estados que com elas se comprometem - constitui área particularmente desafiadora para a pesquisa. Do pesquisador espera-se habilidade no manejo de estratégias atenuantes dos impactos de resistências político-estruturais, para que possa avançar seu trabalho com determinação e firme propósito. O compromisso e engajamento no trabalho de campo de pesquisa sobre tema tão sensível não isentam o pesquisador de se expor a ameaças e riscos políticos. Compõem o elenco de dificuldades para o pesquisador a exposição a sentimentos de culpa e vulnerabilidade na relação com os participantes, desconforto em finalizar o breve relacionamento estabelecido com o participante, levando-o à exaustão psicológica e, por vezes, à necessidade de se autodeclarar enquanto pessoa.

A colaboração internacional em pesquisa tem avançado consideravelmente ao seguir tendências implementadas por equipes multi e interdisciplinares e por reproduzir a composição das equipes assistenciais nas instituições de saúde. ${ }^{3}$ Tais equipes oportunizam fortalecimento e manejo da diversidade cultural entre parceiros internacionais, em especial a pesquisadores principiantes, podendo assim oferecer-lhes suporte para se inserirem nos contextos de pesquisa. $\mathrm{Na}$ condução de pesquisa social sob condições restritivas de liberdade de expressão nas quais um tema sensível possa estar envolto, com proibições implícitas, ${ }^{4}$ uma série de facilitadores guiam a conduta do pesquisador quando este é dela originário. Os facilitadores são: ${ }^{4}$ (a) conhecimento da cultura local, das práticas de controle e dos riscos à liberdade de expressão; (b) consciência das reflexões metodológicas outrora limitadas sobre pesquisas com minorias sociais; (c) conhecimento de formas de acesso à informação e ao campo de pesquisa; (d) revisão da identidade pessoal e profissional do pesquisador, assim como de sua posição na universidade estrangeira ou no país de implantação da pesquisa; e, (e) informação sobre tipo e estado das relações e agendas internacionais interuniversitárias.

\section{REVISÃO DE LITERATURA}

Na globalização, mesclam-se a economia, a tríade ciênciatecnologia-inovação e o desenvolvimento social e humano. Nessa encontram-se os direitos das mulheres que constitui um tema político polêmico, que requer monitoramento global, devido à negligência de vários países em respeitá-los, ${ }^{5}$ e por conectarem aos Objetivos do Desenvolvimento Sustentável, especificamente o Objetivo 5: Alcançar a igualdade de gênero e empoderar todas as mulheres e meninas. ${ }^{6} \mathrm{~A}$ igualdade de gênero deve ser garantida na sociedade também pela eliminação de todas as formas de violência contra as mulheres e meninas nas esferas públicas e privadas. Para isso, preconiza-se a adoção e o fortalecimento de políticas sólidas e legislação específica para promoção da igualdade de gênero e empoderamento dessa população. ${ }^{6}$ Por isto, monitora-se a violação e o aviltamento dos direitos humanos de mulheres e meninas que são temas também presentes na agenda diplomática internacional, ${ }^{7}$ específico para a atenção à proteção das mulheres durante a maternidade e no parto. ${ }^{8,9}$ Nesta área, ressalta-se que o marco conceitual feminista canadense representa um pilar para a ajuda internacional a ser provida pelo governo federal que se concentra na revisão das decisões de sua oferta na cooperação internacional, inclusive na área da pesquisa. ${ }^{10}$

Em sociedades com reconhecidas iniquidades sociais em saúde, o avanço das pesquisas científicas sobre experiências de vida, saúde e morte das populações femininas são essenciais para guiar decisão política e formulação de políticas pautadas em conhecimento científico local. A pesquisa conduzida por enfermeiros e obstetrizes nos países caribenhos e latino-americanos representa apenas $15.9 \%$ da produção científica regional sobre temas da maternidade, nascimento, amamentação e resultados neonatais. ${ }^{11}$ A maioria das pesquisas que se origina no Brasil para obtenção de títulos de pós graduação stricto-sensu apresenta pouca ênfase na pesquisa clínica e discreta implantação de programa individual de pesquisa pelos doutores pós-obtenção do título. ${ }^{11}$

Um tema de inegável relevância humanística, social e política relacionado a múltiplas vulnerabilidades vivenciadas pelas mulheres na assistência obstétrica no Brasil é o da violência obstétrica. ${ }^{12} \mathrm{O}$ parto e o nascimento, por serem eventos holísticos e complexos, no contexto brasileiro, ganham visibilidade global crescente ${ }^{13}$ em razão do apelo ao compromisso e interesse da sociedade na redução da mortalidade materna e de cesarianas desnecessárias, bem como na qualificação da assistência obstétrica e educação profissional em saúde nesse campo específico. ${ }^{14-16}$ A conscientização pelo profissional a respeito desses eventos naturais da vida pode mudar e aprimorar sua práxis.

Lançado em 2000, o Programa de Humanização do Pré-natal e Nascimento (PHPN), ${ }^{17}$ concomitante a movimentos sociais pelos direitos dos consumidores e de direitos humanos, tornou-se um marco em relação ao incentivo à qualificação do pré-natal, à organização, regulação e investimentos na assistência obstétrica e neonatal. Assim, o conceito de humanização na assistência ao parto e nascimento passou a ser adotado também na perspectiva de equidade, cidadania, autonomia e produção de conhecimentos. Não obstante os esforços empreendidos pelo Ministério da Saúde, grandes desafios persistem, entre eles, o modelo de atenção intervencionista, as elevadas taxas de morbi-mortalidade materna e infantil, sobretudo a neonatal, a fragmentação e a pouca resolutividade da rede de atenção, e 
de violência obstétrica, um problema subestimado, que reflete iniquidades persistentes e recorrentes, na assistência ao parto e nascimento no país. ${ }^{14}$ Apesar de iniciativas plurais para coibir a violência obstétrica, vítimas permaneceram "sem voz" e invisíveis ao poderes públicos, culminando, em 2019, com "conotação inadequada"18 ao termo e sua não "recomendação"19 de uso no contexto brasileiro - três meses antes do início do trabalho de campo desta pesquisa objeto do presente artigo.

O marco conceitual da prática profissional reflexiva ${ }^{20}$ guiou esta pesquisa. A reflexão é um processo cíclico que permite ao profissional reaprender a partir de uma dada situação - única ou intrigante - e da informação recém-obtida, resultando na amalgamação de dados, que conduz o profissional a aprimorar ações em situações futuras. Pela reflexão, o profissional pode criticar tacitamente a compreensão que tenha emergido após experiências repetidas, frequentemente no interior da perspectiva de uma prática especializada. Esse marco conceitual influenciou a escolha metodológica do método reflexivo de pesquisa aplicado por nossa equipe de pesquisadores que exercem suas profissões em diversas dimensões da prática de atenção à saúde e bem-estar das mulheres. Assim, o objetivo deste artigo é apresentar os resultados de uma reflexão metodologicamente estruturada sobre o processo de trabalho em todas as fases de uma pesquisa etnográfica internacional no Brasil sobre a implementação do Programa de Humanização do Pré-natal e Nascimento e seus atores sociais.

\section{MÉTODO}

O desenho desta pesquisa qualitativa foi o chamado método reflexivo de pesquisa ${ }^{21}$ conceitualmente baseado na prática profissional reflexiva. ${ }^{20}$ Utilizada como ferramenta nesse método de pesquisa, a reflexão estruturada induz a uma perspectiva de percepção modificada de uma dada situação, conduzindo a novas ideias, com o potencial de revelar temas de análise e engendrar propostas de possíveis soluções. Este método propositalmente promove a avaliação das experiências profissionais por meio de ponderação post-facto, resultando em uma descrição sistemática de fatos, sentimentos, revisão de aspectos negativos e positivos, análise de lições aprendidas, e a reestruturação de soluções potenciais e o desenho de um plano de ação.

O objeto das reflexões concentrou-se em suas participações como co-pesquisadores de um estudo etnográfico multicêntrico realizado em cooperação internacional, multidisciplinar sob a coliderança acadêmica da Ryerson University e a Universidade Federal de Minas Gerais, uma instituição de ensino superior (IES) localizada na região Sudeste do Brasil e em parceria com sete outras IES brasileiras. A implantação se deu na região Norte (estados do Amazonas e Rondônia), Nordeste (estado da Paraíba), Centro-Oeste (Distrito Federal) e Sudeste (estados do Rio de Janeiro e de Minas Gerais), no período de julho de 2019 a março de 2020. Nessa pesquisa reflexiva, os procedimentos aplicaram o seguinte método: ${ }^{21}$ (a) definição do tópico; (b) utilização de perspectivas multidisciplinares; (c) escolha de perspectiva integrativa abrangendo modos de compreender a experiência; e, (d) reconhecimento da legitimidade das experiências únicas dos indivíduos com sua contribuição para o processo de reflexão e recomendações propostas. Neste artigo, apresentamos uma pesquisa qualitativa, metodológica em Enfermagem com o método reflexivo de pesquisa. ${ }^{21}$

Participantes: Cinco enfermeiras, nove estagiários de pesquisa canadenses, sendo sete graduandos de Enfermagem e duas graduandas de Serviço Social, dois Agentes Comunitários de Saúde (ACS), um comunicólogo e uma representante de uma organização internacional.

Organização e análise dos dados: As reflexões individuais como dados primários foram relatadas em textos narrativos curtos, em média com 200 palavras e foram organizadas em quadros (ver quadros 1 a 4). Inspirados no método qualitativo de análise temática, essas reflexões foram submetidas a análise gerando os temas Diplomacia acadêmica e Encontro com a violência obstétrica: significado, impacto e consequência. A interpretação final dessas reflexões compiladas substanciou o desenho de um plano ideal de ação coletiva abordando responsabilidades dos atores sociais na pesquisa multicêntrica em colaboração internacional conforme ilustrado no Quadro 5.

Considerações éticas: A pesquisa original na qual se insere esta pesquisa sincrônica foi aprovada pela Ryerson Research Ethics Board (REB 2019-063) e Conselho Nacional de Pesquisa (2019-3.461.935). A pesquisa pela reflexão crítica pautada nos pensamentos e experiências pessoais dos autores, como docentes, pesquisadores e prestadores de assistência às mulheres é uma atividade de prática criativa.

\section{RESULTADOS}

As reflexões apresentadas nesta seção complementam as evidências produzidas em um contexto de implementação da pesquisa qualitativa enfrentando inúmeras barreiras. Nomear a violência obstétrica, descrevê-la, narrá-la já se mostrava tarefa desafiadora no Brasil, ${ }^{22}$ o que foi explicitado pelo referido documento. ${ }^{18}$ Tratando-se de tendência fortalecedora de ações, por indicar caminhos para a garantia de direitos humanos e para superação das desigualdades de gênero, raça e classe no contexto da assistência obstétrica, a violência obstétrica emergiu nos últimos anos como tema global de pesquisa científica. ${ }^{7}$

O trabalho de campo foi implantado em 27 instituições públicas de saúde, sendo que algumas dessas concluíram o processo de anuência para o desenvolvimento da pesquisa prontamente e, outras, em no máximo seis meses, com impacto no processo de aprovação ética. Duas dessas instituições demandaram um ano para responder à solicitação, sem apresentar justificativas formais, mas com demandas de esclarecimentos relacionadas à logística de campo e a recursos financeiros descritos no projeto (embora se referissem apenas à ajuda de custos para a estada dos estagiários canadenses no Brasil). Além disso, essas mesmas demandas foram apresentadas em tempos distintos e sem a formalidade necessária para registro e diálogos institucionais. Esses atrasos enfrentados pelas coordenadoras postergaram consideravelmente o início da coleta de dados e ameaçaram 
Quadro 1. Narrativa reflexiva da coordenação da pesquisa. Dados da Pesquisa, 2020.

\begin{tabular}{|c|}
\hline Reflexões \\
\hline $\begin{array}{l}\text { Essa perspectiva (da humanização do parto e nascimento) vem se fortalecendo, a partir de experiências de formar } \\
\text { enfermeiros generalistas e especialistas desse campo, e por isso produzir conhecimento por meio dele; pelas experiências } \\
\text { que temos vivido como representantes de associação profissional da Enfermagem, mas fundamentalmente pelo fato de estar } \\
\text { nesse campo há mais de } 30 \text { anos, e esperançosamente - esperança, aqui colocada como concretude histórica, como devir } \\
\text { de corpos imersos numa prática científica, ético-político-social e humanista, como é a Enfermagem -, agenciar-me numa } \\
\text { ação solidária e coletiva como se instaura na produção dessa pesquisa. Daí, todo o sentido de formarmos esse coletivo de } \\
\text { pesquisadores e de instituições públicas brasileiras, numa parceria internacional, em que a Saúde Coletiva e Humanização em } \\
\text { Saúde, no campo específico de atenção obstétrica e neonatal, possam ser potencializadas. Esse foi o caminho que tomamos } \\
\text { por compreender que junta(os), na/pela realização dessa pesquisa, será possível apreender um objeto de estudo que nos } \\
\text { constrange a todas(os) - a Violência Obstétrica - buscando desdobrá-lo em seus desafios: violência/racismo institucional, } \\
\text { violência no parto, violência de gênero, desigualdades em saúde, entre outros, mas que não imobiliza/imobilizará. Trata-se, } \\
\text { portanto, de um objeto que devemos entender como ponto de partida. (Pesquisadora brasileira, responsável pela pesquisa no } \\
\text { Brasil, } 33 \text { anos de experiência como enfermeira obstetra, Belo Horizonte-Brasil) }\end{array}$ \\
\hline $\begin{array}{l}\text { Em um contexto brasileiro de restrito financiamento para a pesquisa em Enfermagem, e o interesse generalizado para } \\
\text { implantar projetos de internacionalização, o status de } 17 \text { professora(e)s universitária(o)s com reconhecidos conhecimentos } \\
\text { clínicos não assegurou o respeito esperado ao negociarem processos de anuências institucionais. Apesar do processo } \\
\text { extremamente sério e formal por mim implantado seguindo preceitos canadenses de cooperação científica internacional, } \\
\text { assustou-me constatar as inúmeras tentativas de ingerência no conteúdo do projeto de pesquisa, questionamento do rigor } \\
\text { metodológico e o total descaso ao tempo para implantação/conclusão. Tal inobservância pode inviabilizar pesquisas com } \\
\text { financiamento estrangeiro com calendários rigorosos. (Pesquisadora brasileira-canadense, responsável internacional pela } \\
\text { pesquisa, } 40 \text { anos de experiência, Toronto-Canadá) }\end{array}$ \\
\hline
\end{tabular}

a permanência dos estagiários no Brasil, repercutindo na viabilidade do projeto.

As reflexões, como aporte metodológico para obtenção dos resultados, indicam que a conscientização crítica acerca da invisibilidade político-social envolvendo o tema da violência obstétrica e o PHPN emergiu por meio do trabalho de campo, enriquecendo tal experiência humana e profissional com crescimento, solidariedade e empoderamento pessoal. Os quadros 1-4 trazem as reflexões de copesquisadores e colaboradores em fases distintas da pesquisa. A imersão cultural durante coleta de dados ofereceu olhar diferenciado sobre a assistência obstétrica, tal como percebida por parte da equipe canadense, pesquisadora e estagiários, uma vez que vivenciaram a imersão no trabalho de pesquisa de campo interpretada por seus referênciais profissionais de justiça, inclusão e equidade social, de proteção aos direitos humanos das mulheres e respeito a autonomia da clientela somados à sua responsabilidade profissional e compromisso cidadão. Os copesquisadores eram oriundos da Faculty of Community Services da Ryerson University cujos programas de ensino são guiados por uma filosofia educacional que almeja mudanças sociais em indivíduos e em comunidades, para impulsionar mudanças positivas e sólidas com paixão, rigor e curiosidade para desenvolver o conhecimento substanciando a ação. A educação capacita para a abordagem de desafios sociais e ambientais complexos e a construção de uma sociedade mais justa mediante a edificação conjunta com as comunidades, por meio de mudanças sociais. ${ }^{23}$

Graças às bolsas de pesquisa outorgadas pelo programa canadense Mitacs Globalink Research Award aos nove estagiários de pesquisa, esses permaneceram 12 semanas no Brasil para o trabalho de campo. Esse trabalho incluiu a imersão cultural e social, vivências de relações de gênero, trocas sociais, artísticas e de lazer e também aprendizado sobre a estrutura legal e operacional do Sistema Único de Saúde (SUS). Nas vivências em ambientes sociais e culturais diversos, realizaram visitas a organizações comunitárias, leituras de políticas e normas de saúde, revisaram material da mídia popular sobre o tema da violência obstétrica e mantiveram um diário de campo estruturado e reflexivo.

Esses estagiários canadenses se sensibilizaram para reconhecerem e lidarem (ao menos, inicialmente) com questões de racismo e discriminação, e iniquidades sociais em contexto clínico e na pesquisa. Ao se integrarem nos programas de graduação em Enfermagem, eles aprenderam sobre educação e prática de Enfermagem na assistência pré-natal, ao parto e puerpério. Nas instituições de saúde, eles ainda identificaram o desequilíbrio de poder entre os profissionais e a clientela feminina. Aprenderam também sobre violência obstétrica multidimensional identificando-a prontamente ao encontrá-la. As reflexões pontuais desses estagiários canadenses oriundas de suas experiências nas diversas regiões do Brasil indicam a multiplicidade de percepções baseadas em realidades locais de assistência pré-natal e ao parto. Tais reflexões interconectam-se no que tange à realidade observada quanto à humanização da assistência obstétrica e aos direitos humanos, bem como a interiorização das reflexões sobre a percepção da experiência estudantil relacionada ao contexto de Toronto e das expectativas para suas futuras práticas profissionais no Canadá ou em outro contexto internacional.

Na região Norte, emergiram questões maiores de violação de direitos humanos: 
Quadro 2. Narrativa reflexiva sobre a entrada no campo e atividades de colaboração. Dados da Pesquisa, 2020.

\begin{tabular}{|c|}
\hline \\
\hline $\begin{array}{l}\text { A partir da vivência com as participantes, pude perceber a sutileza das ações; por exemplo, quando a mulher grávida se } \\
\text { percebe vulnerável, e este estado corrobora para a permissividade de alguns atos, sendo que, depois disso, podem ter } \\
\text { diferente entendimento para a mesma situação. Então, não se restringe aos procedimentos sem consentimentos, já que } \\
\text { em muitos casos, as mulheres concordaram com ocitocina; em ficar quietas no leito; em espera prolongada, ao invés de } \\
\text { agendamento de horário; em assentir com a estrutura do local em que foram atendidas, mesmo percebendo aspectos a } \\
\text { melhorar, visto por elas mesmas como exigência demasiada e, assim, contentar-se em serem atendidas, apenas. Essa questão } \\
\text { não se reduz à disseminação de informação em saúde. Portanto, o desafio de implementar o programa de humanização de } \\
\text { pré-natal e nascimento inclui efetividade no processo de cuidado, no sentido coletivo, e superando o repasse de informações } \\
\text { para mulher dos seus direitos, da criança e família, mas que as pessoas se sintam merecedoras de assistência de melhor } \\
\text { qualidade. Para tanto, a sensibilização de gestores da saúde, educação, trabalho, ciência, tecnologia e comunicações } \\
\text { para se constituir como base de ação governamental para que possa munir as pessoas de modo geral, pois se a mulher } \\
\text { não reivindicar, por mais letrada em saúde que se sinta, os outros o façam. E, ao conversar com mulheres sobre violência } \\
\text { obstétrica, tive a oportunidade também de autorreflexão sobre minha condição profissional. (Pesquisadora brasileira, } 20 \text { anos } \\
\text { de experiência em Saúde Pública, Brasília-Brasil) }\end{array}$ \\
\hline $\begin{array}{l}\text { O envolvimento no [mídia social] foi muito diferencial, foi muito proveitoso, pois teve que ser feito todo um trabalho } \\
\text { junto com a responsável internacional, a nossa mídia responsável, para que o conteúdo fosse adequado ao público-alvo. } \\
\text { E conseguimos ver isso nas redes sociais, conseguimos chegar a esse foco, que teve muita participação das mulheres, } \\
\text { conseguimos êxito em cima da resposta junto ao [mídia social]. Os ACS se sentiram importantes, sofreram também... porque } \\
\text { teve [x número] que acabou participando, contanto seus relatos. Eles viram a importância da participação deles nesse projeto, } \\
\text {... foi um momento em que eles puderam mostrar a grandeza do seu trabalho, pôde entender a grandeza do seu trabalho. } \\
\text { (ACS, colaborador na divulgação e no recrutamento,18 anos de experiência, São Gonçalo-Brasil) }\end{array}$ \\
\hline $\begin{array}{l}\text { Fiquei muito feliz em saber que esses estagiários estão desenvolvendo metodologias, estão pensando na saúde mais ampla } \\
\text { para todo mundo, porque são estagiários de todos os lugares. Foi muito importante, como observadora, participante das } \\
\text { reuniões, observar que a área da saúde está cada vez mais se reinventando, cada vez mais querendo melhorar ..., tentar } \\
\text { ver direitos de todas as mulheres, grávidas e por que não dos seus futuros bebês que possam vir a ter esse conhecimento, } \\
\text { para que a violência obstétrica não se perpetue, que outros profissionais sejam educados ..., com isso eles detenham o } \\
\text { conhecimento e essa questão de violência obstétrica acabe de uma vez por todas. Esse é o ponto crucial do conhecimento, } \\
\text { este é o ponto mais sensato de educação em saúde para que as futuras mães não passem mais por nenhum problema de } \\
\text { violência obstétrica. Este é o ponto que mais me deixou satisfeita em fazer parte desse projeto todo, de saber que há pessoas, } \\
\text { há profissionais que querem mudar esse conceito, querem mudar essa falha na saúde, que é a violência obstétrica. (ACS, } \\
\text { colaboradora no recrutamento, } 18 \text { anos de experiencia, São Gonçalo-Brasil) }\end{array}$ \\
\hline
\end{tabular}

Esse projeto me ajudou a entender que a violência ...começa com a tentativa de controlar o corpo das mulheres.... experiências esclareceram os perigos de fazer julgamentos de valor sobre o comportamento da cliente como profissional de saúde e me ensinaram a importância de questionar meus próprios preconceitos internos. (tradução livre, graduanda de Enfermagem, Porto Velho).

\footnotetext{
A violência obstétrica é evidente (conforme comentários compartilhados) mas a grande maioria carece desse conhecimento. Um profissional afirmou que "assim que a mãe é internada, ela corre o risco de violência obstétrica", no entanto, mais de $90 \%$ das mulheres entrevistadas afirmaram que a violência obstétrica era um novo conceito para elas e acreditavam que essas ações eram "normais". Com isso, ficou evidente a relação entre a falta de educação em saúde / direitos à saúde e as implicações da violência obstétrica. (tradução livre, graduanda de Enfermagem, Manaus).
}

Na região Centro-Oeste, a única dupla Enfermagem-Serviço Social da equipe trouxe nas reflexões perspectivas complementares sobre culturas sociais de assistência e de prática:

No hospital, percebi algumas violações dos direitos humanos, principalmente a falta de privacidade das mulheres durante o parto. (tradução livre, graduanda de Serviço Social, Brasília).

Eu observei muitas intervenções desnecessárias que comprometeram a segurança da mãe para promover um parto rápido... senti que a prioridade de um parto rápido causava às pacientes a impressão de receber cuidados com compaixão. O foco em intervenções desnecessárias intrinsecamente remove a autonomia da mãe de decidir por si mesma o que é seguro, melhor e conveniente para ela. (tradução livre, graduanda de Enfermagem, Brasília)

Já na região Nordeste, chamou atenção a aceitação acrítica e passiva da clientela feminina: 
Quadro 3. Narrativa reflexiva sobre a coleta de dados. Dados da Pesquisa, 2020.

\begin{tabular}{|c|}
\hline Reflexões \\
\hline $\begin{array}{l}\text { Muitas vezes, durante a coleta de dados, surgiu a questão de saber se as mulheres estão cientes ou não de terem sofrido } \\
\text { violência. Isso levanta a questão do que define violência e o que define uma vítima. Muitas mulheres que sofrem violência } \\
\text { obstétrica não se percebem violadas. A estória do que aconteceu com elas pode ser retratada de maneiras diferentes, } \\
\text { e podemos ser os primeiros a atribuir a palavra "vítima" a elas. Mesmo assim, todas essas mulheres são sobreviventes } \\
\text { dessa violação de seus direitos humanos fundamentais. Violações desses direitos, promulgada por meio de formas físicas, } \\
\text { emocionais, espirituais e econômicas de violência, tentando manter as mulheres "em seu lugar". Eles não abrem espaço } \\
\text { para a mulher que fala, que é barulhenta e sem medo de mostrar dor, ou a mulher ... que pode estar tendo um filho sem a } \\
\text { estrutura familiar convencional. Em vez disso, eles querem apenas mulheres submissas e obedientes. No entanto, mesmo } \\
\text { muitas das mulheres que têm medo de ficar caladas, que agem "perfeitamente", são incapazes de escapar da ameaça de } \\
\text { violência durante os momentos vulneráveis do parto. (tradução livre, graduanda de Serviço Social, Niterói-Brasil) }\end{array}$ \\
\hline $\begin{array}{l}\text { Minha experiência colhendo dados em pesquisas qualitativas sobre a violência contra a mulher conscientizou-me sobre minha } \\
\text { capacidade limitada de ajudar mulheres que compartilharam suas dores morais, psicológicas e espirituais. Em um grupo focal } \\
\text { com ACS mulheres (zona rural, Rio de Janeiro) nesta pesquisa, duas delas não relataram experiências das cadastradas, em } \\
\text { uma explosão de catarse revelaram experiências pessoais com a violência obstétrica. A primeira relatou, como parturiente, } \\
\text { a violência física sofrida, em prantos, sob o olhar atônito e a postura respeitosa das demais agentes comunitários de saúde } \\
\text { (e minhas preces silenciosas para que Deus ajudasse-nos a agir com solidariedade em silêncio cuidadoso). A segunda, como } \\
\text { mãe de uma parturiente adolescente relatou chorando uma interação chocante com a equipe de Enfermagem composta } \\
\text { por mulheres indiferentes que promoveram a violência institucional. Os pedidos dessa mãe, para que permanecesse } \\
\text { acompanhando sua filha apavorada pela situação de parto de risco foram ignorados. Exceto por uma das atendentes solidária } \\
\text { que comprometeu-se a "olhar mais" pela adolescente em trabalho de parto. Revoltante constatar como as mulheres na } \\
\text { Enfermagem também perpetuam tal monstruosidade nos espaços institucionais. (Pesquisadora brasileira-canadense, } \\
\text { responsável internacional da pesquisa, } 40 \text { anos de experiência, Toronto -Canadá) }\end{array}$ \\
\hline $\begin{array}{l}\text { Tive a oportunidade de ouvir um relato de uma puérpera imigrante de } 45 \text { anos. Um ano após seu parto ela ainda carregava a } \\
\text { dor por seus direitos terem sido desrespeitados. Segundo ela, não teve comorbidades na gestação, tinha uma doula e seguiu } \\
\text { o pré-natal na expectativa do parto normal. Por ser imigrante, na sua cultura nem se pensa em optar por um parto cesárea, } \\
\text { no entanto, no dia em que entrou em trabalho de parto seguiu para o hospital, ligou para o médico que a acompanhou, para } \\
\text { seus pais que estavam no Brasil e seu marido, todos a postos para a chegada do bebê e eis a surpresa, seu médico Ihe informou } \\
\text { que devido à sua idade seria melhor um parto cesária. Relatou que o ambiente era claustrofóbico, que não lhe dava nenhum } \\
\text { conforto, com as opiniões todas contrárias ao plano de parto que havia feito, também ficou com medo do que pudesse } \\
\text { acontecer com seu filho caso não aceitasse os conselhos que lhe levavam ao parto cesárea. Um ano após o parto ela ainda está } \\
\text { processando a invisibilidade da violência que sofreu, coisa que não conseguiu fazer no dia do parto devido às pressões invisíveis } \\
\text { que sofreu. (Pesquisadora brasileira, } 24 \text { anos de experiência em Enfermagem Obstétrica, Brasília-Brasil) }\end{array}$ \\
\hline
\end{tabular}

\begin{abstract}
....as mulheres não têm escolha quanto ao parto e aceitam qualquer cuidado que recebam. Também descobri que as mulheres estão satisfeitas em receber cuidados desrespeitosos na maternidade, desde que o bebê seja entregue em segurança - "os fins justificam os meios". Não ter opções aos seus cuidados aumenta a suscetibilidade à violência... (tradução livre, extrato do documento de reflexão estruturada, graduanda de Enfermagem, João Pessoa).
\end{abstract}

As experiências dos estagiários de Enfermagem e de Serviço Social na região Sudeste revelaram as interconexões entre práticas institucionalizadas extensivas ao contexto comunitário:

\footnotetext{
Ciclos de violência são sutis. Isto me ajudou a internalizar a importância do nosso trabalho aqui no Brasil e compreender por que sistemas e políticas precisam ser avaliados. Políticas precisam ser definidas e orientadas para o empoderamento
}

do público. (tradução livre, extrato do documento de reflexão estruturada, graduanda de Enfermagem, Rio de Janeiro).

A primeira visita domiciliar... acompanhada pelo agente comunitário de saúde. A entrevista foi curta; no entanto, foi uma troca aberta e honesta, que revelou relatos pessoais de violência obstétrica da mulher e de sua mãe. Atribuo muitas informações compartilhadas à presença do agente de saúde da comunidade, que havia construído um relacionamento com a usuária do serviço, que permitiu que informações confidenciais fluíssem facilmente. Como futura assistente social, senti-me inspirada a ver esse tipo de relacionamento profissional-cliente construído sobre a confiança mútua. (tradução livre, graduanda de Serviço Social, Niterói).

Durante um grupo focal com agentes comunitários de saúde...foi impressionante ver o número de agentes dispostos a fornecer suas ideias sobre a humanização 
Quadro 4. Narrativa reflexiva sobre a análise e disseminação dos achados. Dados da Pesquisa, 2020.

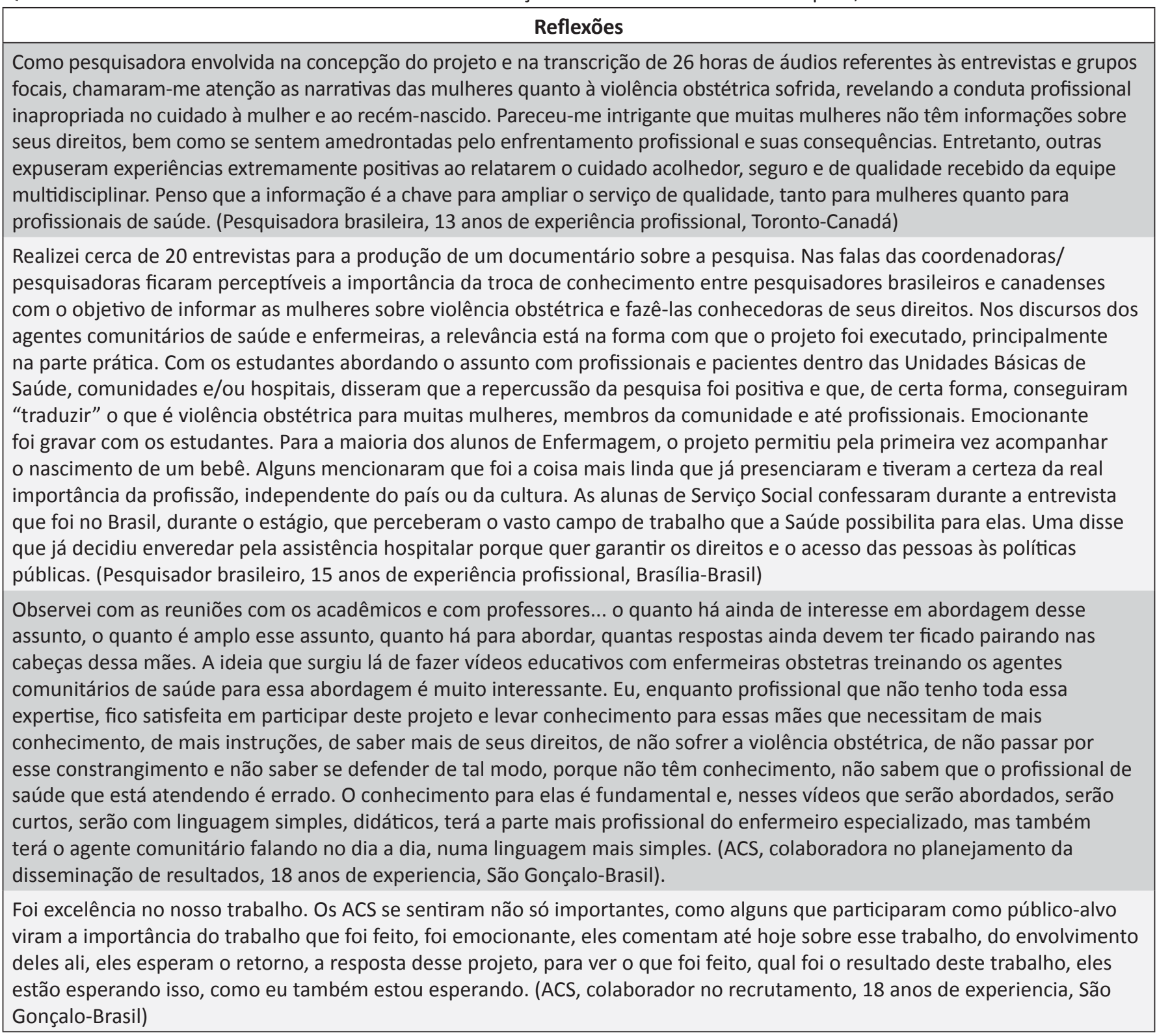

do trabalho e do nascimento. (tradução livre, graduando de Enfermagem, Juiz de Fora).

Essa experiência e tudo o mais que encontrei durante meu período no campo me permitiram crescer e aprender como pessoa e profissional de muitas maneiras que só seriam possíveis pela integração na comunidade, presença física no campo etnográfico e experimentando a cultura e o cenário como ele é. (tradução livre, graduanda de Enfermagem, Belo Horizonte)

Podemos, assim, ressaltar que entendemos que os achados e resultados trouxeram em si a possível influência na formulação de programas e políticas públicas. Superar comportamentos profissionais autoritários e atualizar procedimentos técnicos obsoletos e danosos na assistência ao parto é um grande desafio para todos.

As iniciativas para desenvolvimento e a formulação de programas e de políticas públicas exige o empoderamento das mulheres, o reconhecimento da violência obstétrica, a mobilização da sociedade, e ainda, representantes dos poderes públicos e do sistema de saúde privado. (Pesquisadora da equipe brasileira, com 30 anos de experiência na área de desenvolvimento e implantação de políticas de gênero e família em organização internacional, Brasília)

As reflexões indicam a sensibilidade sobre o tema e o silêncio existente e imposto sobre o objetivo final do PHPN, ou seja, o 
de coibir a violência obstétrica. Sob múltiplas manifestações da violência institucionalizada, foram relatadas resistência confrontada na rede hospitalar, negligência e questionamentos distorcidos nos espaços políticos de autorização para a anuência institucional e demora por comitê de ética, colocando em risco o calendário de conclusão da condução da pesquisa exigido por agência estrangeira de fomento. A análise temática revelou dois temas: Diplomacia acadêmica, e Encontro com a violência obstétrica: significado, impacto e consequência. Na perspectiva da diplomacia acadêmica, ao se posicionar os resultados em contexto maior de política institucional, evidenciou-se que dificuldades relacionadas às questões de diplomacia da pesquisa internacional e à preparação ao acolhimento da pesquisa em colaboração internacional foram enfrentadas. Esta interpretação implica geopolítica crítica do conhecimento ${ }^{24}$ que propõe 0 avanço do espectro de ações das relações internacionais no desenvolvimento da pesquisa científica, com mobilização de recursos estratégicos e reconhecimento do poder real e simbólico da ciência e da tecnologia. A significação cultural do poder e da influência científica que o Brasil exerce e pode exercer compõem tal cenário. Tal entendimento da diplomacia internacional do conhecimento requer diálogo entre os pares e respeito a agendas de trabalho previamente acordadas e aprovadas.

O encontro com a violência obstétrica permitiu a criação de seu significado, o reconhecimento de seu impacto social e as possíveis consequências para os profissionais e a clientela. Das reflexões emergiram indícios de relatos de que a violência obstétrica encontra-se enraizada na prática obstétrica como uma forma de controle sobre os corpos femininos cuja manifestação acontece em ações sutis. Ações essas que, quando normalizadas, conduzem as mulheres a serem gratas por receberem qualquer forma de assistência obstétrica. A normalização das várias violações dos direitos das mulheres, a pressão e as táticas coercitivas pelo medo, por vezes, desempenham o papel de criar expectativas para as mulheres parturientes que, no final, as induz à obediência e ao silêncio.

Por meio de reflexões, os estagiários canadenses questionaram suas premissas, julgamentos, sentimentos, ações e reações. A pesquisa qualitativa de temas sensiveis com indivíduos vulneráveis a danos, maus-tratos e desrespeito utiliza a autorreflexão para conectar experiências na pesquisa com questões éticas, políticas e sociais, ${ }^{25}$ concentrando-se na ética da prática, das questões cotidianas, e de situações específicas e inesperadas. Ao refletir, os pesquisadores articulam e manejam suas emoções relacionadas à justiça social segundo a sua posicionalidade, reciprocidade e emotividade ante os participantes da pesquisa. Faz-se necessário a aproximação com a pesquisa que se dá fundamentalmente pelo contato direto com o participante durante a coleta de dados. $\mathrm{O}$ desgaste emocional devido ao tema estudado se supera com a empatia emocional, o distanciamento do objeto de pesquisa e pelas variadas formas de apoio e suporte que o supervisor de campo possa oferecer. ${ }^{26}$

As reflexões permitiram aos copesquisadores brasileiros "construir" e "analisar" seus próprios resultados de pesquisa e ponderar sobre a possibilidade de melhorar suas próprias práticas, enquanto os canadenses se confundiram com a gama de violações de direitos que combinavam direitos humanos das mulheres com os direitos obstétricos. Por meio de reflexões conjuntas e pontuais desenvolveu-se uma visão mais clara sobre algumas expressões da violência obstétrica e dos desafios distintos enfrentados pelas mulheres e profissionais quanto à implementação plena da PHPN. Escrever sobre experiências e refletir sobre elas representa o investimento cognitivo, emocional e psicológico que se faz enquanto pesquisador ${ }^{27}$ ao se coletar dados, decodificar significados e construir novos entendimentos. Tal evidência reitera que a reflexão conjunta contribui para assegurar aos pesquisadores certo nível de segurança emocional e propiciar um tipo de consciência emancipatória. ${ }^{28}$ Os embates pessoais e profissionais vivenciados despertam essa consciência, em particular quando um diário de reflexão é mantido como o que foi feito pelos estagiários de pesquisa.

Entendeu-se que a violação sistemática de direitos, de fato, representa o sofrimento ao qual se submetem os cidadãos mais privados de serviços e direitos, em geral os desfavorecidos, as mulheres, as crianças e os idosos. As reflexões induziram à conclusão de que existe um desafio triplo para se implantar uma agenda de pesquisa socialmente inclusiva, transformadora e capaz de produzir evidência científica para subsidiar a formulação de políticas públicas com sustentação e factibilidade: (1) Tornar a violência obstétrica um tema chamativo para a academia e os apoiadores políticos, criadores de políticas, gestores e profissionais; (2) Transformar a violência obstétrica em um tema de reclamações e denúncias para trazê-lo para o mundo da academia permitindo aos indivíduos ocupar todos os espaços sociais; e, (3) Desafiar a mobilização da sociedade para que compartilhem com as mulheres os papéis de liderança neste movimento de humanização. Nos resultados, reitera-se o pensamento sobre a reflexão crítica ${ }^{21: 64}$, transferindo-o ao contexto da prática profissional em pesquisa (tradução livre):

Estou convencido de que é crucial desenvolver a credibilidade acadêmica e intelectual do processo de reflexão crítica para o entendimento da experiência da prática profissional. Sua capacidade de iluminar os modos nos quais nos engajamos com o nosso trabalho, são complexos, integrados e fluidos resultando em novas e inestimáveis reflexões profundas sobre a prática profissional e sobre nós mesmos como seres humanos no interior de tais modos de trabalhar.

O plano de ação (ver quadro 5) resultante da reflexão coletiva e de suas interpretações contém 13 recomendações relacionadas ao planejamento e ao trabalho de coleta de dados para futuras pesquisas internacionais com universidades brasileiras, uma vez parceiras em pesquisa multicêntrica. Ressaltamos que a maioria das recomendações almejam a harmonização e a efetividade de ações administrativas e técnicas para a alta qualidade e eficácia do trabalho de pesquisa em campo. 
Quadro 5. Recomendações para plano de ação de pesquisa internacional multicêntrica. Dados da Pesquisa, 2020.

Náreas de possíveis ações
- Articular diálogo entre as comissões de ética locais, nacionais e internacionais sobre modus operandi em pesquisa com foco
prioritário na proteção dos participantes.
- Mobilizar o setor de assuntos internacionais para assegurar a apresentação formal dos copesquisadores internacionais às
instituições colaboradoras locais.
- Incrementar engajamento das pró-reitorias de pesquisa das universidades receptoras dos projetos para viabilizar
procedimentos de comissões de ética em tempo hábil, honrando calendário de trabalho por agências internacionais de
fomento.
Na esfera administrativa Estadual/Distrital/Municipal referente aos campos de coleta de dados
- Apresentar o projeto de pesquisa utilizando abordagem audiovisual ao corpo clínico e à administração institucional,
ampliando entendimento sobre a pesquisa.
- Promover diálogo institucional sobre o valor social da pesquisa.
No âmbito da sociedade civil
- Estabelecer parcerias formais para recrutamento com associações profissionais e comunitárias.
- Expandir a publicidade sobre a pesquisa em todos os campos de coleta de dados utilizando-se de todas as mídias sociais.
No âmbito da equipe de pesquisa
- Agregar graduandos como copesquisadores em formação com deveres, direitos e responsabilidades similares com os demais
membros da equipe.
- Desenvolver material promocional sobre a pesquisa, considerando diferentes públicos-alvo, priorizando material audiovisual.
- Harmonizar métodos de trabalho e estratégias de comunicação pré-existentes nas sub-equipes de pesquisa de diferentes
países.
- Mobilizar o potencial de graduandos e pós-graduandos locais e estrangeiros conectando-os aos programas de pesquisa de
seus mentores-pesquisadores.
- Treinar os estudantes-assistentes de pesquisa com uso de simulação realística, para entrarem em campo de pesquisa local
atentando para diferenças relativas ao contexto de vida e acadêmico de origem.
No âmbito da coleta de dados
- Assegurar que a coleta de dados sob tema sensível seja conduzida por pesquisadores aptos a responderem às situações
emocionais desestabilizantes dos participantes.

\section{DISCUSSÃO}

Os copesquisadores canadenses e brasileiros com perfis distintos de experiência profissional, revestidos ou não de poderes institucionais, agregaram a essa pesquisa espectro de olhares e vozes internas e externas delineando suas perspectivas pessoais, sociais e culturais. Apesar dos níveis diferenciados de conhecimento em pesquisa, explorou-se ideias de profissionais que foram direta e remotamente validadas pelos participantes e corroboradas pela variedade de evidências coletadas. Este conjunto de elementos foi crucial para a validade epistemológica da pesquisa reflexiva.

As reflexões ainda indicaram que, nos dez campos de implantação da pesquisa, a violência obstétrica constitui-se um tema que potencialmente pode silenciar muitos profissionais, apesar de se tornar objeto de questionamento nas interações entre os pares no contexto clínico (e.g., na asfixia perinatal e assistência ao parto de baixa qualidade). Projetada no contexto do pré-natal e no puerpério, a violência obstétrica associa-se a interesses globais e equidade em saúde global negligenciando os Objetivos de Desenvolvimento Sustentável relacionados às questões de gênero e equidade. ${ }^{6}$ Trata-se de um tema central para a saúde coletiva, devido às suas relações com a mortalidade materno-infantil, violência contra a mulher, nascimento pré-termo. ${ }^{8,9}$ Ao se pesquisar o PHPN, deu-se voz aos oprimidos dentro da comunidade profissional, de discentes e de usuários (homens e mulheres) do SUS. A humanização em saúde e na assistência às mulheres no parto constitui um marco, a rota e o alvo para enfrentarmos juntos o desafio de fazer pesquisa como produção do coletivo. Portanto, podemos trilhar caminhos metodológicos para interferência nas práticas de assistência, gestão e formação na saúde e também produção de conhecimentos. A humanização como conceito-experiência fornece a base para a ampliação de seu uso ético-estético-político no campo da assistência obstétrica por meio de um (novo) olhar analítico-avaliativo, para (trans) formar as realidades de trabalho e de cuidado. ${ }^{15}$

Essa proposta coaduna com a lacuna identificada na pesquisa brasileira em saúde ${ }^{29}$ referente ao distanciamento 
no saber-fazer, ou seja, da produção do conhecimento até sua aplicação na prática profissional em saúde. A pesquisa, ao traduzir as realidades sociais das usuárias do SUS, destaca benefícios do conhecimento gerado para as mesmas. Ainda, os resultados podem indicar áreas em que mudanças para inovar práticas no contexto do SUS sejam necessárias para a redução das desigualdades sociais em saúde. ${ }^{28}$ Para enfrentar e superar as barreiras da implementação ampla do PHPN, o movimento com esse coletivo ampliado de pesquisa, sob o imperativo ético de produzir inclusão, traz pesquisadores e instituições ao caminho da humanização como política do compromisso global de fazer a ciência do cuidado avançar com alteridade.

Ousa-se, portanto, na convocação geral à ideia de coletivamente, como pesquisadores, docentes, profissionais de saúde, e discentes convidar mulheres e homens para politizar o caminho da produção de conhecimentos renovando valores, interesses e produzindo novos espaços coletivos de vozes amplificadas. Nesse projeto de colaboração entre membros da academia e da comunidade, para a produção de conhecimentos com potencial de mudanças sociais, se prevê desafios impostos por identidade de gênero e sexualidade requerendo até a negociação de papéis sociais. Tal como alertado por Lenette e cols, ${ }^{29}$ pesquisas do tipo participatória são associadas a movimentos sociais - como aqui relatado - que são geralmente conduzidas por cientistas mulheres que vivenciam o impacto de seu gênero no trabalho de campo. Cientistas mulheres na pesquisa participativa aproximam-nas da perspectiva feminista cujos objetivos últimos focalizam o cuidado do outro, o empoderamento e a justiça social. ${ }^{29}$

\section{CONCLUSÃO E IMPLICAÇÃO PARA A PRÁTICA}

A reflexão estruturada enquanto método de pesquisa possibilitou um processo inovador de aprendizagem para uma equipe internacional de pesquisa navegando em distintas culturas universitárias e sociais de pesquisa. A presença em campos de pesquisa de docentes e discentes e suas vivências singulares, difíceis e exitosas, estimulou a renovação de práticas e estratégias para a consecução de objetivos da pesquisa. $O$ aprendizado propiciado por essa experiência tornou-se uma fonte inspiradora única, não apenas para futuros projetos de pesquisa, mas subsidia, ainda, a prática docente sobre pesquisa em saúde global. Destacando-se a de que a liderança exercida por pesquisadores enfermeiros em uma equipe de pesquisa internacional deve ser entendida como uma mudança necessária e revolucionária.

Uma pesquisa sobre reflexões dos próprios autores tem como possível limitação sua restrita profundidade em traduzir toda uma gama de emoções, sentimentos, e aprendizados especialmente quando realizada com interações de conhecimentos locais e estrangeiros. O que se vislumbra como ação no contexto da pesquisa para a Enfermagem global deve-se ao resultado dos múltiplos momentos de reflexão sobre o trabalho de campo da pesquisa (não captado aqui em sua integralidade e complexidade) como o realizado pelos supervisores de pesquisa em campo, protagonizado por docentes de Enfermagem brasileiros em conjunção com os estagiários canadenses apoiados por graduandos de Enfermagem brasileiros. A isto somou-se o resultado da utilização do método de reflexão estruturada na pesquisa de modo conjunto estimulando a equipe a almejar a elevação do nível de sofisticação da prática da pesquisa em contexto internacional expondo-se a críticas dos pares e melhorando a qualidade do trabalho de campo de pesquisa.

\section{AGRADECIMENTOS}

Paloma Terra (Parteira Prática Independente/Rede pela Humanização do Parto e Nascimento). Dra. Gilmária Salviano Ramos (Universidade Federal de Viçosa) pela revisão técnica, contribuindo para elevação da qualidade deste manuscrito. Sandra Andrade do Val pela revisão idiomática de português.

\section{FINANCIAMENTO}

Mitacs Globalink Research Award 2018 recebido por Vanessa Fofie (\#IT 12953), Dakota Carrie (\#IT 12407), Francesca Aviv (\#IT 12406), Milena Oliva (\#IT 12475), Dorin d'Souza (\#IT 12470), Hannah Stahl (\#IT 12476), Hannah Argumedo-Stenner (\#IT 12401), Hilary Hwu (\# IT 12473) e John Tadeo (\#IT 12952). Ryerson University President Office e Faculty of Community Services, Seed Grant 2019.

\section{CONTRIBUIÇÕES DOS AUTORES}

Desenho da proposta de reflexão. Margareth Santos Zanchetta. Walterlânia Silva Santos. Kleyde Ventura de Souza. Alecssandra de Fátima Silva Viduedo. Hannah Argumedo-Stenner. Dakota Carrie. Francesca Aviv. Hilary Hwu. Hannah Stahl. Vanessa Fofie. Dorin d'Souza. Milena Oliva. John Tadeo. Edwaldo Costa. Francisco Vilela. Andréa Carvalho. Haydée Padilla Vda de Escobar. Ingryd Cunha Ventura Felipe.

Levantamento de informações. Margareth Santos Zanchetta. Walterlânia Silva Santos. Kleyde Ventura de Souza. Alecssandra de Fátima Silva Viduedo. Hannah Argumedo-Stenner. Dakota Carrie. Francesca Aviv. Hilary Hwu. Hannah Stahl. Vanessa Fofie. Dorin d'Souza. Milena Oliva. John Tadeo. Edwaldo Costa. Francisco Vilela. Andréa Carvalho. Haydée Padilla Vda de Escobar. Ingryd Cunha Ventura Felipe.

Análise de dados. Margareth Santos Zanchetta. Walterlânia Silva Santos. Kleyde Ventura de Souza. Alecssandra de Fátima Silva Viduedo. Hannah Argumedo-Stenner. Dakota Carrie. Francesca Aviv. Hilary Hwu. Hannah Stahl. Vanessa Fofie. Dorin d'Souza. Milena Oliva. John Tadeo. Edwaldo Costa. Francisco Vilela. Andréa Carvalho. Haydée Padilla Vda de Escobar. Ingryd Cunha Ventura Felipe.

Interpretação dos resultados. Margareth Santos Zanchetta. Walterlânia Silva Santos. Kleyde Ventura de Souza. Alecssandra de Fátima Silva Viduedo. Hannah Argumedo-Stenner. Dakota Carrie. Francesca Aviv. Hilary Hwu. Hannah Stahl. Vanessa Fofie. Dorin d'Souza. Milena Oliva. John Tadeo. Edwaldo Costa. Francisco Vilela. Andréa Carvalho. Haydée Padilla Vda de Escobar. Ingryd Cunha Ventura Felipe.

Redação e revisão crítica do manuscrito. Margareth Santos Zanchetta. Walterlânia Silva Santos. Kleyde Ventura de Souza. Alecssandra de Fátima Silva Viduedo. Hannah Argumedo-Stenner. Dakota Carrie. Francesca Aviv. Hilary Hwu. Hannah Stahl. Vanessa 
Fofie. Dorin d'Souza. Milena Oliva. John Tadeo. Edwaldo Costa. Francisco Vilela. Andréa Carvalho. Haydée Padilla Vda de Escobar. Ingryd Cunha Ventura Felipe.

Aprovação da versão final do artigo. Margareth Santos Zanchetta. Walterlânia Silva Santos. Kleyde Ventura de Souza. Alecssandra de Fátima Silva Viduedo. Hannah ArgumedoStenner. Dakota Carrie. Francesca Aviv. Hilary Hwu. Hannah Stahl. Vanessa Fofie. Dorin d'Souza. Milena Oliva. John Tadeo. Edwaldo Costa. Francisco Vilela. Andréa Carvalho. Haydée Padilla Vda de Escobar. Ingryd Cunha Ventura Felipe.

Responsabilidade por todos os aspectos do conteúdo e a integridade do artigo publicado. Margareth Santos Zanchetta. Walterlânia Silva Santos. Kleyde Ventura de Souza. Alecssandra de Fátima Silva Viduedo. Hannah Argumedo-Stenner. Dakota Carrie. Francesca Aviv. Hilary Hwu. Hannah Stahl. Vanessa Fofie. Dorin d'Souza. Milena Oliva. John Tadeo. Edwaldo Costa. Francisco Vilela. Andréa Carvalho. Haydée Padilla Vda de Escobar. Ingryd Cunha Ventura Felipe.

\section{EDITOR ASSOCIADO}

Antonio José de Almeida Filho

\section{REFERÊNCIAS}

1. LeeYO, Lee RM. Methodological research on "sensitive" topics: a decade review. Bull Methodol Sociol. 2012 abr 12;114(1):35-49. http://dx.doi. org/10.1177/0759106312437139.

2. Dickson-Swift V, James EL, Kippen S, Liamputtong P. Doing sensitive research: what challenges do qualitative researchers face? Qual Res. 2007 ago 1;7(3):327-53. http://dx.doi.org/10.1177/1468794107078515.

3. Pinho DLM, Reeves S. An interprofessional international research collaboration: exploration of key opportunities and challenges. J Interprof Care. 2020 fev 13;1-5:1-5. http://dx.doi.org/10.1080/13561820.2020.1 711716. PMid:32053410.

4. Yusupova G. Exploring sensitive topics in an authoritarian context: an insider perspective. SSQ. 2019 abr 16;100(4):1459-78. http://dx.doi. org/10.1111/ssqu. 12642.

5. Yamin AE. Power, politics and knowledge claims: sexual and reproductive health and rights in the SDG era. Glob Policy. 2019 jan 29;10(S1, Suppl 1):52-60. http://dx.doi.org/10.1111/1758-5899.12598.

6. World Health Organization. Transforming our world: The 2030 agenda for sustainable development [Internet]. Geneva:World Health Organization; 2019 [cited 2020 Apr 24]. Disponível em: https://nacoesunidas.org/ pos2015/agenda2030/

7. Ali HM, Boddy J, Ewart J. Exploring the use of public relations in organising activism: implications for addressing gender-based violence in the developing world. Asia Pacific Public Relations Journal [Internet]. 2016 [cited 2020 Jul 26];17(2): 46-61. Disponível em: https://www.pria. com.au/public/38/files/Asia\%20Pacific\%20PR\%20Journal/Volume\%20 17\%20(2)/77-3-1-PB.pdf

8. Lokugamage AU, Pathberiya SDC. Human rights in childbirth, narratives and restorative justice: a review. Reprod Health. 2017;4(17):1-8. http:// dx.doi.org/10.1186/s12978-016-0264-3.

9. World Health Organization. Prevention and elimination of disrespect and abuse during childbirth [Internet]. Geneva: World Health Organization; 2014 [cited 2020 abr 24]. Disponível em: https://www.who.int/ reproductivehealth/topics/maternal_perinatal/statement-childbirth/en/

10. Government of Canada (CA). Canada's Feminist International Assistance Policy; [cited 2020 abr 24]. Canada: Government of Canada; [aprox 3 telas]. Disponível em: https://www.international.gc.ca/world-monde/ issues_development-enjeux_developpement/priorities-priorites/policypolitique.aspx?lang=eng

11. Iribarren S, Stonbraker S, Larsen B, Santos I, Faria R, Goés FSN et al. Clinical nursing and midwifery research in Latin American and Caribbean countries: a scoping review. Int J Nurs Pract. 2018;24(2):e12623. http:// dx.doi.org/10.1111/ijn.12623. PMid:29436102.

12. Grilo Diniz CS, Rattner D, Lucas d'Oliveira AFP, de Aguiar JM, Niy DY. Disrespect and abuse in childbirth in Brazil: social activism, public policies and providers' training. Reprod Health Matters. 2018;26(53):19-35. http://dx.doi.org/10.1080/09688080.2018.1502019. PMid:30106349.

13. Bohren MA, Vogel JP, Hunter EC, Lutsiv O, Makh SK, Souza JP et al. The mistreatment of women during childbirth in health facilities globally: a mixed-methods systematic review. PLoS Med. 2015;12(6):1-32. http:// dx.doi.org/10.1371/journal.pmed.1001847. PMid:26126110.

14. Lansky S, Souza KV, Peixoto ERM, Oliveira BJ, Diniz CSG, Vieira NF et al. Obstetric violence: influences of the Senses of Birth exhibition in pregnant women childbirth experience. Cien Saude Colet. 2019;24(8):2811-24. http://dx.doi.org/10.1590/1413-81232018248.30102017.PMid:31389530.

15. Santos Filho SB, de Souza KV. Methodology to articulate the process of training intervention-evaluation in the professional education in nursing Cien Saude Colet. 2020;25(1):79-88. http://dx.doi.org/10.1590/141381232020251.28322019. PMid:31859857.

16. Barbosa JDM, Modena CM. Obstetric violence in the daily routine of care and its characteristics. Rev Lat Am Enfermagem. 2018;26:e3069. http://dx.doi.org/10.1590/1518-8345.2450.3069. PMid:30517571.

17. Portaria n. 569, de $1^{\circ}$ de junho de 2000 (BR). Programa de Humanização no Pré-natal e Nascimento. Diário Oficial da União, Brasília (DF), 8 junho 2000 [cited 2020 jul 13]. Disponível em: http://bvsms.saude.gov. br/bvs/saudelegis/gm/2000/prt0569_01_06_2000_rep.html

18. Despacho de 03 de maio de 2019 (BR). Secretaria de Atenção à Saúde, Departamento de Ações Programáticas Estratégicas. Diário Oficial da União, Brasília (DF), 3 maio, 2019 [cited 2020 jul 13]. Disponível em: https://sei.saude.gov.br/sei/controlador_externo. php?acao=documento_conferir\&codigo_verificador $=90876218$ codigo_crc=1A6F34C4\&hash_download=c4c55cd95ede706d0b729845a 5d6481d07e735f33d87d40984dd1b39a32d870fe89dcf1014bc76a 32d2a28d8f0a2c5ab928ff165c67d8219e35beb1a0adb3258\&visualizacao= 1\&id_orgao_acesso_externo=0

19. Recomendação n 29/2019 de 07 de maio de 2019 (BR). Inquérito Civil. Ministério Público Federal, São Paulo, 7 maio 2019 [cited 2020 jul 13]. Disponível em: http://www.mpf.mp.br/sp/sala-de-imprensa/docs/ recomendacao_ms_violencia_obstetrica.pdf/

20. Schön DA. The reflective practitioner: How professionals think in action New York: Basic Books; 1983.

21. Fook J. Developing critical reflection as a research method. In: Higgs $\mathrm{J}$, Titchen A, Horsfall D, Bridges D, editors. Creative spaces for qualitative researching. 2011. p. 55-64. doi: http://dx.doi.org/10.1007/978-94-6091761-5_6.

22. Dias M, Machado VEM. Obstetric violence in Brazil: An integrated multiple case study. Int J Nurs Midwifery. 2018;8(2):117-28. [citado 2020 Jul 13]. Disponível em: http://www.eajournals.org/wp-content/ uploads/Obstetric-Violence-in-Brazil.pdf

23. Ryerson University. Faculty of Community Services. About [Internet]. Toronto, ON: Ryerson University [citado 2020 jul 13]. Disponível em: https://www.ryerson.ca/fcs/about/.

24. Popolo D. Science and international relations: Brazil and geopolitics of knowledge. BJRL. 2016;5(2):292-315. http://dx.doi.org/10.36311/22377743.2016.v5n2.04.p291.

25. Shaw RM, Howe J, Beazer J, Carr T. Ethics and positionality in qualitative research with vulnerable and marginal groups. Qual Res. 2019;•••:1-17. http://dx.doi.org/10.1177/1468794119841839.

26. Simpson KL, Wilson-Smith K. Undergraduates' experience of preparedness for engaging with sensitive research topics using qualitative research. Psychol Teach Rev. 2017;23(1):30-40.

27. Malacrida C. Reflexive journaling on emotional research topics: ethical issues for team researchers. Qual Health Res. 2007;17(10):1329-39. http://dx.doi.org/10.1177/1049732307308948. PMid:18000072.

28. Santos AO, de Barros FPC, Delduque MC. Health research in Brazil: challenges to be faced. Saúde Debate. 2019;43(5):126-36. http://dx.doi. org/10.1590/0103-11042019s511.

29. Lenette C, Stavropoulou N, Nunn C, Kong ST, Cook T, Coddington Ket al. Brushed under the carpet: examining the complexities of participatory research. Research for All. 2019;3(2):161-79. http://dx.doi.org/10.18546/ RFA.03.2.04. 